\title{
PRODUZINDO PODCASTS NA EDUCAÇÃO FÍSICA ESCOLAR: POSSIBILIDADES E DESAFIOS DURANTE O ENSINO REMOTO EMERGENCIAL
}

Khalmel Gabriel Lima de Oliveira, PPEDU/UFSJ, handkal@yahoo.com.br; https://orcid.org/0000-0003-1288-6112

Diego de Sousa Mendes, PPEDU/UFSJ, diegomendes@ufsj.edu.br; https://orcid.org/0000-0002-2297-5883

\begin{abstract}
RESUMO
O contexto da Covid-19 não só reforçou a importância das discussões acerca das Tecnologias Digitais de Informação e Comunicação em contextos educacionais, mas também levou gestores e professores a implementar estratégias pedagógicas em consonância com as particularidades do Ensino Remoto Emergencial (ERE). Assim, o presente estudo, de viés qualitativo e do tipo Pesquisa-Ação, tem como objetivo refletir uma experiência pedagógica desenvolvida em aulas de Educação Física escolar, a partir da produção de podcasts. Foram produzidos onze podcasts sobre a temática do racismo no esporte. Por fim, a utilização de podcasts como recurso pedagógico constituiu parte de um novo arranjo didático, que provocou maior participação e engajamento de parcela dos estudantes.
\end{abstract}

Palavras-Chave: podcast; Ensino Remoto Emergencial; Educação Física escolar; Pesquisa-Ação; mídia-educação

\section{PRODUCING PODCASTS IN PHYSICAL EDUCATION CLASSES: POSSIBILITIES AND CHALLENGES DURING EMERGENCY REMOTE TEACHING}

\section{ABSTRACT}

The context of Covid-19 not only reinforced the importance of discussions about Digital Technologies of Information and Communication in educational contexts, but also led managers and teachers to implement pedagogical strategies in line with the particularities of Emergency Remote Teaching. Thus, this qualitative study, developed along the lines of Action-Research, discusses a pedagogical experience developed in Physical Education classes, consisting of a production of podcasts. Eleven podcasts were produced on the theme of racism in sport. Finally, the use of podcasts as a pedagogical resource was part of a new didactic arrangement that caused greater participation and engagement by part of the students involved.

Keywords: podcast; Emergency Remote Learning; Physical Education; Action-Research; media education

\section{INTRODUÇÃO}

Em virtude da pandemia da Covid- $19^{1}$, grande parte das instituições de ensino ao redor do País tiveram que fechar temporariamente as portas como medida de combate e proteção ao coronavírus. Tão logo fechadas as portas, iniciou-se uma intensa movimentação por parte dos sistemas e redes de ensino, na busca por estratégias capazes de garantir aos estudantes o direito constitucional de acesso à educação (BRASIL, 2016). Desse modo, o Ministério da Educação (MEC) publicou a Portaria $\mathrm{n}^{\circ}$ 
343, de 17 de março de $2020^{2}$, que versa sobre a substituição das aulas presenciais por aulas em meios digitais, durante o período de calamidade sanitária.

Assim, de modo contingente, emergiu o Ensino Remoto Emergencial (ERE), que teve como intuito manter as atividades escolares de forma não presencial. Tal circunstância teve impactos sobre o planejamento e a realização das atividades pedagógicas desenvolvidas pelos professores, trazendo à tona as Tecnologias Digitais de Informação e Comunicação (TDIC) como possibilidade para a efetivação do processo de ensino-aprendizagem. Diante desse novo cenário, professores dos diferentes níveis de ensino (da Educação Básica até a Educação Superior) tiveram que refletir sobre as reconfigurações, os desafios e os desdobramentos do ERE.

O presente estudo tem como objetivo refletir acerca de uma experiência pedagógica desenvolvida em aulas de Educação Física escolar, durante o ERE. Trata-se de uma pesquisa de viés qualitativo (MINAYO, 2002) e do tipo Pesquisa-Ação (TRIPP, 2005). Desse modo, a temática do racismo no esporte foi abordada mediante à produção de podcasts, valendo-se o docente da articulação dos pressupostos da mídia-educação (FANTIN, 2011; BÉVORT; BELLONI, 2008) com o conteúdo esporte. A experiência pedagógica ocorreu junto aos estudantes de três turmas do $8^{\circ}$ ano do ensino fundamental de uma escola pública do interior de Minas Gerais.

$\mathrm{O}$ artigo está organizado da seguinte maneira: Na seção 2, é apresentada uma revisão teórica a respeito dos tópicos envolvidos na experiência pedagógica, sendo eles a mídia-educação, a Educação Física escolar e a utilização de podcasts como recurso pedagógico; a seção 3 descreve a metodologia utilizada no estudo; a seção 4 apresenta as observações e os resultados obtidos a partir dos dados empíricos; e a seção 5 apresenta as considerações finais do artigo.

\section{FUNDAMENTAÇÃO TEÓRICA}

As circunstâncias impostas pela pandemia reforçaram a importância das discussões acerca das TDIC em contextos educacionais e levaram gestores e professores a implementar, às pressas, estratégias pedagógicas em consonância com as particularidades do ambiente on-line. Nesse sentido, esta seção se propõe a discutir a utilização dos podcasts como recurso pedagógico em aulas de Educação Física escolar, pelo prisma da mídia-educação. Na subseção 2.1, é apresentado o conceito de mídia-educação, bem como as possibilidades de articulá-lo com a Educação Física escolar. Na subseção 2.2 apresenta-se uma definição acerca do podcast e discute-se a utilização desta mídia como recurso pedagógico.

\subsection{Mídia-educação e Educação Física escolar: uma articulação possível}

A mídia-educação é uma proposta educativa que contempla as mídias como ferramentas pedagógicas e como objetos de estudo (BÉVORT; BELLONI, 2009). Em vista disso, Fantin (2011) amplia a noção a respeito da mídia-educação, entendendo-a como uma condição de educação, permeada por uma cidadania instrumental e de pertencimento, em direção ao acesso à produção de saber e à democratização de oportunidades educacionais. Ainda segundo Fantin (2011), uma educação para as mídias deve considerar a formação de um sujeito ativo, criativo e crítico, além de colocar em circulação os mais diversos suportes midiáticos no curso do processo de ensino-aprendizagem.

Tendo em vista que grande parte das experiências dos jovens com as TDIC ocorrem fora do ambiente escolar (jogar games, ouvir músicas, postar fotos, entre outros), é pertinente refletir sobre como essas experiências poderiam ser abordadas e 
problematizadas nos ambientes educacionais de forma crítica e criativa (FANTIN, 2011, BUCKINGHAM, 2018). Assim sendo, considerando a multiplicidade de ambientes on-line, tais possibilidades poderiam constituir espaços/tempos propícios para o exercício da autonomia, da criação e da autoria. Diante disso, a mídia-educação apresenta-se como uma perspectiva teórico-metodológica oportuna para a práxis pedagógica da Educação Física.

Concebemos a Educação Física como o componente curricular da Educação Básica que trata, pedagogicamente, da cultura corporal de movimento no interior da escola. A cultura corporal de movimento compreende "saberes corporais, experiências estéticas, emotivas, lúdicas e agonistas" (BRASIL, 2018, p. 213) e representa um dos fenômenos mais importantes nos meios de comunicação de massa e na economia (BETTI; ZULIANI, 2002). Os esportes, as danças, as ginásticas, as lutas, as práticas de aptidão física se tornam, a cada dia que passa, "produtos de consumo (mesmo que apenas como imagens) e objetos de conhecimento e informação amplamente divulgados ao grande público" (BETTI; ZULIANI, 2002, p. 74).

Uma vez que redes sociais, sites especializados, revistas, jornais, noticiários televisivos e outras formas de comunicação de massa disseminam opiniões e ideias sobre a cultura corporal do movimento, é de fundamental importância que compreendamos esse fenômeno à luz das inúmeras relações que o permeiam. Assim, o esporte, enquanto conteúdo da Educação Física escolar, deve ser abordado nas situações de ensino-aprendizagem não apenas com o intuito de os alunos aprenderem habilidades motoras e desenvolverem capacidades físicas, mas também com o objetivo de formar cidadãos críticos, que saibam posicionar-se frente às múltiplas manifestações esportivas, como, por exemplo, o esporte que circula nas mídias (BETTI, 2006).

Hoje somos todos potenciais consumidores do esporte, seja como telespectadores, seja como torcedores em quadras e estádios ou como praticantes. Diante disso, é muito importante que a Educação Física escolar conduza os estudantes a uma compreensão acerca das nuances do esporte, de modo que esses sujeitos possam não só apreciá-lo técnica e esteticamente, mas também conhecer as informações políticas, históricas e os interesses econômicos atrelados a essa prática corporal. Portanto, mediante a possibilidade de articular os pressupostos da mídia-educação com a Educação Física escolar, a seguir, exploraremos o podcast como meio para consubstanciar essa articulação.

\subsection{A utilização de podcasts como recurso pedagógico}

De acordo com Primo (2005), o podcast tem como objetivo a distribuição, direta e atemporal, de arquivos de áudio e vídeo por meio da internet. A criação do vocábulo podcast se deu a partir da junção da palavra $i P O D$, aparelho da Apple de reprodução de MP3, com broadcast, que significa "transmissão" em inglês (KLERING et al., 2021).

No caso da educação, esse suporte midiático pode abranger públicos diversos, como estudantes da educação básica e acadêmicos. Além disso, o podcast pode contemplar pessoas com deficiência visual, a fim de contribuir com o desenvolvimento, o aprendizado e a imaginação desses sujeitos (OLIVEIRA et al., 2020).

A produção de podcasts constitui uma estratégia pedagógica que pode ser prazerosa e benéfica, pois reúne alguns fatores que propiciam sua inserção no ambiente escolar. Entre esses fatores estão a utilização de recursos simples e de baixo custo, a possibilidade de contemplar os conhecimentos prévios dos estudantes e a facilidade de acessar o conteúdo produzido a qualquer hora e lugar (KLERING et al., 2021). 
Conforme Oliveira et al. (2020), o uso do podcast possibilita que o processo educativo aconteça mesmo em condições contingentes como o ERE, pois instaura uma forma dinâmica e acessível de aprendizagem, uma vez que lança mão de um material que pode ser retomado a qualquer momento. Outro aspecto relevante a respeito da utilização pedagógica do podcast é que ele possibilita aos estudantes não só consumir, mas também produzir conteúdo digital.

Além disso, agregar o podcast como recurso pedagógico pode abrir espaço para novas formas de interação com a informação, oferecendo aos estudantes envolvidos uma experiência multimídia, que ultrapassa a simples escuta (CARVALHO, 2011). Nesse sentido, a escolha do podcast para a composição da experiência pedagógica esteve assentada em seu caráter hipermidiático e em sua linguagem híbrida, uma vez que esse recurso se utiliza de som, signos visuais e signos verbais.

\section{METODOLOGIA}

A Pesquisa-Ação (PA) se constituiu através de uma experiência pedagógica realizada na terceira etapa letiva do ano de 2020, em uma escola pública do interior de Minas Gerais, com os estudantes ${ }^{3}$ de três turmas do $8^{\circ}$ ano do ensino fundamental. Com o intuito de garantir o anonimato dos participantes da pesquisa, foram utilizados nomes fictícios na escrita deste artigo. Foram utilizados como instrumentos para a produção dos dados empíricos: diário de campo, capturas de tela (screenshots) e gravações.

Conforme Tripp (2005), a PA compõe as práticas de investigação-ação, as quais se organizam por meio de ciclos. Desse modo, o ciclo básico de investigação-ação estabelece dois eixos (investigação e ação) e quatro etapas (planejar, agir, descrever e avaliar). Assim, em nosso estudo, o eixo da investigação fundou-se na seguinte problemática: Como ampliar a dialogicidade nas aulas remotas de Educação Física escolar? A problemática da pesquisa emergiu da vivência de um dos autores do artigo, durante as etapas letivas que precederam a realização do estudo, quando foi observado que o formato das aulas remotas de Educação Física restringia a troca dialógica entre professor e estudantes. De acordo com Abreu (2018), o acesso à comunicação propiciado pelas novas mídias, atualmente, oferece múltiplas possibilidades para uma Educação pautada no diálogo. Em acréscimo, para dar conta do aspecto da dialogicidade, apoiamo-nos em Souza et al. (2009), que concebem a mídia-educação (especialmente a mídia-educação na Educação Física escolar) como possibilidade conceitual e metodológica para a formação de alunos críticos, reflexivos e produtores de conhecimento na escola. Ou seja, mediante a postura crítica desses sujeitos no processo de recepção de informações, é possível ampliar horizontes, com base no diálogo e nas múltiplas mediações decorrentes do ambiente educacional. Assim, nossa proposição de pesquisa buscou fomentar a troca dialógica no ERE, pois defendemos um ensino-aprendizagem assentado na premissa de que estudantes não só recebem informações, mas também são produtores de conhecimento.

O eixo da ação constituiu-se com a proposição de uma interlocução pedagógica, pautada na mídia-educação, com abordagem à temática do racismo no esporte, por meio da produção autoral de podcasts. A Pesquisa-Ação compreendeu quatro etapas. Primeiramente, houve o planejamento, que previu a realização da interlocução pedagógica em duas semanas, com momentos síncronos e assíncronos. Na sequência, aconteceu a implementação da interlocução planejada. Tal etapa foi organizada conforme a estrutura a seguir: 1) envio de material pedagógico (formato de texto digital) por intermédio do WhatsApp; 2) encontro síncrono on-line por meio do Jitsi Meet ${ }^{4}-\mathrm{a}$ duração de cada encontro síncrono foi de 50 minutos; e 3) momento de interação/síntese 
no WhatsApp - esse momento ocorria na sequência do encontro síncrono, tinha duração média de 25 minutos e era guiado pelo professor a partir de questões problematizadoras. A etapa seguinte foi a descrição dos acontecimentos da experiência pedagógica, consubstanciada pelos registros do diário de campo, das capturas de tela e das gravações. Por fim, a etapa de avaliação se deu por meio da apreciação dos materiais produzidos pelos estudantes, bem como pelos diálogos entre o professor e os estudantes, ocorridos nos momentos síncronos e assíncronos.

Na primeira semana da experiência pedagógica, os objetivos foram (re)conhecer, explorar e pesquisar os elementos básicos de um podcast, tais como construção de roteiro, estratégias para gravação/produção, formatos de distribuição, entre outros. $\mathrm{O}$ envio do material pedagógico ocorreu na segunda-feira daquela semana e continha um texto base explanando a respeito do podcast ("O que é?"; "Como surgiu o termo?"; “Como ouvir?"; "Como criar seu próprio podcast?"), além de links para acesso a vídeos tutoriais. Após o compartilhamento do material pedagógico, foi aberto um canal de comunicação com os estudantes por meio do WhatsApp, para que eventuais dúvidas pudessem ser sanadas e orientações específicas encaminhadas. Na quinta-feira, ocorreu o encontro síncrono on-line, quando o professor explanou para os estudantes a respeito do racismo no esporte, utilizando-se de dados estatísticos, de aspectos da legislação e de uma dinâmica interativa. À vista disso, os conteúdos abordados ao longo da semana foram concatenados através do momento de interação/síntese em um grupo específico no WhatsApp.

$\mathrm{Na}$ segunda semana, o objetivo estabelecido para os estudantes foi produzir um podcast que tratasse do racismo no esporte. Isso posto, o material pedagógico enviado no início da semana versou sobre as orientações para a produção do podcast: formato do arquivo da gravação (áudio ou vídeo), produção de roteiro e tempo limite do material. $\mathrm{O}$ trabalho pôde ser feito de forma individual ou em grupo, sendo que os estudantes que optaram por realizar a atividade em grupo tiveram que se organizar remotamente. $\mathrm{O}$ encontro síncrono on-line foi definido junto aos estudantes como o momento para apresentar os materiais elaborados, porém, em função do número de podcasts produzidos, houve a necessidade de realizar dois encontros em sequência. Após os encontros, foi realizado o momento de interação/síntese via WhatsApp, quando os estudantes receberam feedbacks referentes aos materiais por eles produzidos, além de ter sido o espaço/tempo para a avaliação da experiência pedagógica.

Por fim, a análise dos dados realizou-se por meio de abordagem qualitativa (MINAYO, 2002). Nesse particular, os registros do diário de campo foram organizados e sistematizados com o intuito de efetivar a produção dos dados empíricos. Os dados produzidos tiveram como foco o aspecto dialógico estabelecido em momentos específicos da interlocução pedagógica, a saber, trocas de mensagem no WhatsApp, trocas de mensagem no chat do Jitsi Meet e trechos relevantes decorrentes das gravações do encontro síncrono.

\section{RESULTADOS E DISCUSSÃO}

O resultado da experiência pedagógica foi a produção de onze podcasts. No total, 39 estudantes efetivaram a proposta pedagógica, sendo que quatro optaram por produzir o material individualmente e os demais se organizaram em grupos (sete grupos). Todos enviaram o roteiro e o arquivo digital do podcast. Os roteiros foram entregues em formato de texto digital, e os podcasts variaram entre arquivos de vídeo e áudio. Foi possível observar que os estudantes se valeram de diferentes estratégias para 
a produção dos podcasts, entre elas: entrevista com convidado, debate entre os integrantes do grupo e explanação baseada no roteiro previamente elaborado.

De modo geral, todos os materiais elaborados atenderam aos requisitos pré-estabelecidos e apresentaram correlação com o que Fantin (2011, p. 30) denominou os "quatro C" da mídia-educação: cultura, crítica, criação e cidadania. Nesse sentido, o encontro síncrono on-line da primeira semana trouxe à tona o engajamento dos estudantes, que se utilizaram do chat para expressar suas percepções a respeito da experiência com a produção dos podcasts. Foi o caso da estudante Nanda, que fez a seguinte ponderação por meio de uma mensagem no chat: "Eu vejo quase todo dia no apple podcasts, tem muitos podcasts legais". Em resposta à mensagem de Nanda, o estudante Bryan complementou: "editar o podcast tá sendo legal, estou aprendendo um monte de coisas".

A troca de mensagens entre os estudantes apresentada acima evidencia que o "consumo" de mídias, como o podcast, é algo corriqueiro e que desperta o interesse do público jovem. Além disso, a conversa dá indícios de que a articulação entre a Educação Física escolar e a produção de mídias, especificamente o formato podcast, teve aceitação por parte dos estudantes. De acordo com Oliveira et al. (2020), o podcast constitui um recurso midiático com conteúdo fluido e resumido, o qual pode apresentar resultados positivos para o aprendizado de estudantes, como a memorização e o reconhecimento do conteúdo estudado.

Um aspecto relevante acerca da produção de podcasts, que esteve presente nos materiais produzidos pelos estudantes, foi a dimensão da criatividade evocada pela mídia-educação (FANTIN, 2011; BÉVORT; BELLONI, 2009). A figura 1 apresenta a capa de um dos podcasts produzidos, apontando que, em alguns casos, os estudantes extrapolaram as orientações prévias e investiram na dimensão estética do material midiático, corroborando a dimensão criativa apontada por Fantin (2011). De acordo com Bévort e Belloni (2009), entre os objetivos da mídia-educação está a produção de obras midiáticas criativas, sobretudo entre crianças e jovens.

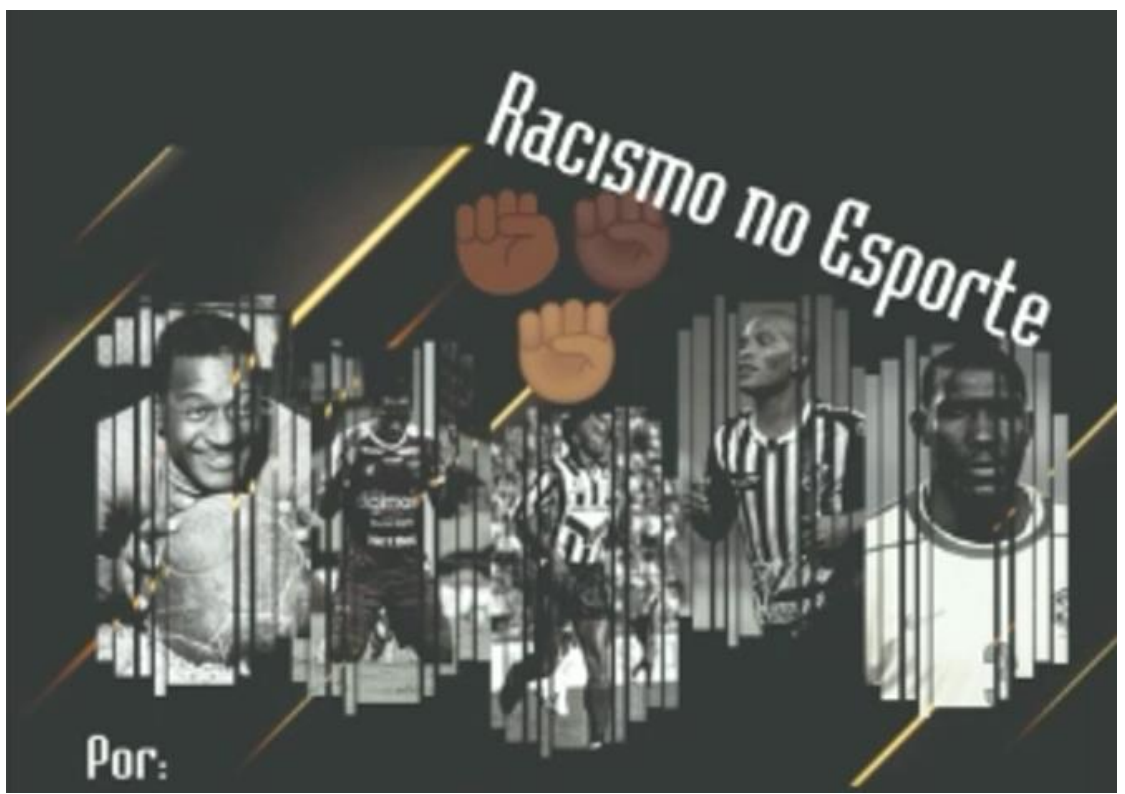

Figura 1 - Capa de um podcast produzido pelos estudantes.

Fonte: Acervo dos autores.

Durante um debate ocorrido no momento de interação/síntese (figura 2), foi possível observar que os estudantes apresentaram criticidade e uma perspectiva de 
exercício da cidadania. Esses aspectos também dialogam com os quatro $C$ de Fantin (2011).

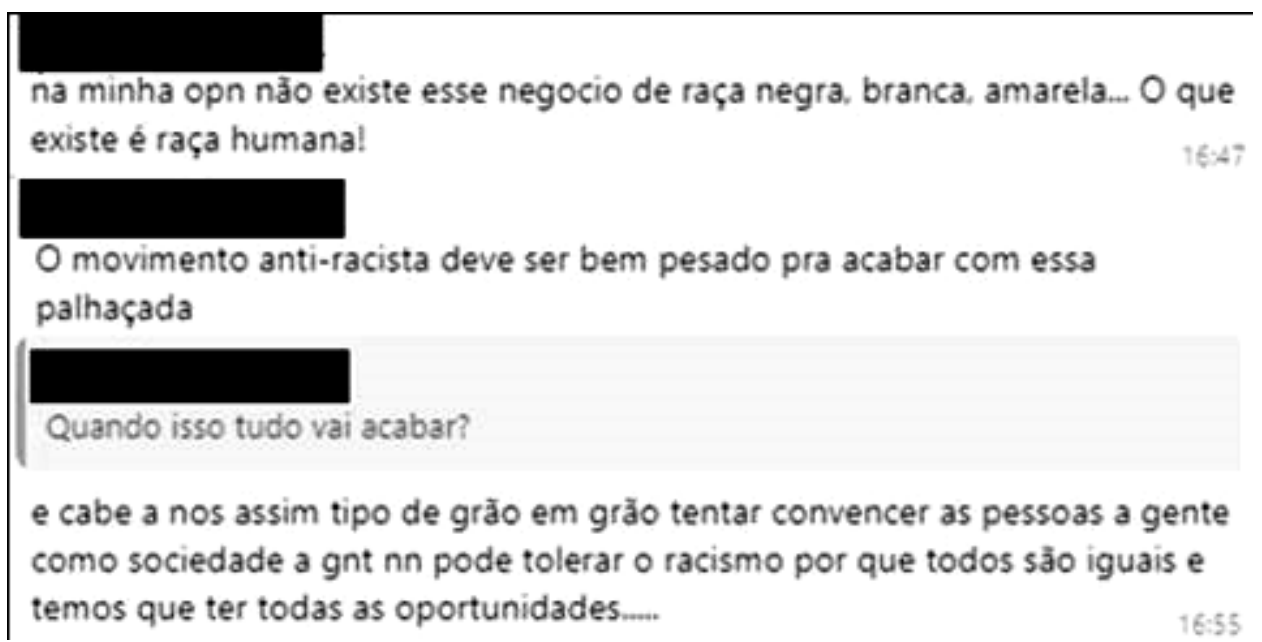

Figura 2 - Captura de tela decorrente do momento de interação/síntese via WhatsApp. Fonte: Acervo do autor.

A implementação de podcasts como parte de uma estratégia metodológica mostrou-se potente e configurou uma possibilidade para aulas de Educação Física durante o ERE. O uso do podcast, mídia amplamente presente na contemporaneidade, quando de sua articulação com o conteúdo esporte, possibilitou e potencializou o compartilhamento e a troca de experiências relativas às temáticas da Educação Física escolar. Outro fator relevante a respeito da produção de podcasts foi o caráter colaborativo (PRIMO, 2005) que se instaurou para a produção dessa mídia. Para mais, percebemos que a presença da mídia-educação se efetivou como um importante aporte teórico-metodológico para o ensino-aprendizagem da Educação Física escolar.

Entretanto, mesmo com a ampla difusão das TDIC e com o crescente acesso à internet nos lares brasileiros, é importante ressaltar alguns desafios. Segundo dados do Instituto Brasileiro de Geografia e Estatística (IBGE), em levantamento realizado no quarto trimestre de 2018, foi constatado que 45,9 milhões de brasileiros com 10 anos de idade ou mais não têm acesso à internet (IBGE, 2018). Somado a esse dado, é preciso considerar também que, quando existe o acesso à rede, em muitos casos, as conexões apresentam má qualidade e tráfego de dados limitado (CGIB, 2018).

Diante disto, é importante dizer que não contamos com a participação de todos os estudantes durante o desenvolvimento da experiência pedagógica, tanto nos momentos assíncronos como nos momentos síncronos. Assim, é preciso considerar que o ERE trouxe uma série de implicações para a participação (ou não) dos estudantes nesse formato contingente e pouco conhecido. Também é preciso ponderar que o uso exclusivo de recursos que dependam do acesso à internet e da disponibilidade das TDIC, tendo em vista o ensino-aprendizagem no ERE, ainda é limitante e pode ocasionar a exclusão de estudantes.

Além disso, a desigualdade de acesso pode manifestar-se também no âmbito das competências digitais (STEVANIM, 2020) ou do capital cultural (BOURDIEU; PASSERON, 2014) que os estudantes (não) possuem. Para Bordieu e Passeron (2014), capital cultural se refere ao conjunto de conhecimentos que um indivíduo adquire ao longo da vida e que o favorecem (ou não) em seu processo de aprendizagem. Portanto, acreditamos que a escola, ao lançar mão de experiências pedagógicas que enfatizem a 
utilização das TDIC e a produção de mídias, pode contribuir substancialmente com a formação de indivíduos críticos, criativos e conscientes.

\section{CONSIDERAÇÕES FINAIS}

Não obstante a questão do ensino-aprendizagem no contexto do ERE constituir uma problemática complexa e repleta de fatores interferentes, as práticas desenvolvidas nesse período são relevantes e podem fundar novas investigações envolvendo a Educação Física escolar e a mídia-educação em outros contextos. Embora as condições estruturais de acesso à internet e as condições objetivas do ERE não permitissem que a atividade fosse acessível a todos estudantes, concluímos que a produção midiática em formato podcast, no âmbito da Educação Física escolar e pautada pela mídia-educação, mostrou-se relevante para o desenvolvimento do conteúdo esporte durante o ERE, constituindo parte de um novo arranjo didático que provocou maior participação e engajamento de uma parcela dos estudantes.

${ }^{1}$ Conforme a Fundação Osvaldo Cruz, "o nome Covid é a junção de letras que se referem a (co)rona (vi)rus (d)isease, o que na tradução para o português seria 'doença do coronavírus'. Já o número 19 está ligado a 2019, quando os primeiros casos foram publicamente divulgados”. Disponível em https://portal.fiocruz.br/pergunta/por-que-doenca-causada-pelo-novo-coronavirus-recebeu-o-nome-decovid-19

${ }^{2}$ Disponível em https://www.in.gov.br/en/web/dou/-/portaria-n-343-de-17-de-marco-de-2020-248564376

${ }^{3}$ Para participar da pesquisa os colaboradores tiveram que assinar um Termo de Assentimento Livre e Esclarecido (TALE) e, por serem eles menores de idade, seus pais/responsáveis tiveram que assinar um Termo de Consentimento Livre e Esclarecido (TCLE). A pesquisa foi aprovada pelo Comitê de Ética (CEP - UFSJ) por meio do Certificado de Apresentação de Apreciação Ética (CAAE) $\mathrm{n}^{\circ}$ 36902920.4.0000.5151.

${ }^{4}$ Jitsi é um conjunto de projetos de código aberto que permite realizar videoconferências. Parte integrante desses projetos, o Jitsi Meet, especificamente, permite a realização de conferências na internet, enquanto outros projetos da comunidade Jitsi permitem recursos como áudio, discagem, gravação e transmissão simultânea. Disponível em https://jitsi.org/about/.

\section{REFERÊNCIAS}

ABREU, A. V. T. Teorias curriculares: Dialogicidade, produção de conhecimento e sua relação com as mídias digitais. Revista Inova Ciência \& Tecnologia, Uberaba, v. 4, n. 2, p. 61-69, jul/dez, 2018. Disponível em: http://periodicos.iftm.edu.br/index.php/inova/article/view/452. Acesso em: 8 dez. 2021.

BETTI, M.; ZULIANI, L. R. Educação Física escolar: Uma proposta de diretrizes pedagógicas. Revista Mackenzie de Educação Física e Esportes, São Paulo, v. 1, n. 1, p. 73-81, 2002.

BETTI, M. "Imagens em ação": Uma pesquisa-ação sobre o uso de matérias televisivas em programas de educação física do ensino fundamental e médio. Revista Movimento, Porto Alegre, v. 12, n. 2, p. 95-120, maio/ago., 2006. 
BÉVORT, E.; BELLONI, M. L. Mídia-Educação: Conceitos, história e perspectivas. Educação e Sociedade, Campinas, v. 30, n. 109, p. 1081-1102, set./dez., 2009. Disponível em http://www.cedes.unicamp.br. Acesso em: 28 set. 2021.

BOURDIEU, P.; PASSERON, J. C. A reprodução: Elementos para uma teoria do sistema de ensino. Petrópolis: Vozes, 2014.

BUCKINGHAM, D. Going critical: On the problems and the necessity of media criticism. In: David Buckingham Files, [s. 1.], 2018. Disponível em:

https://ddbuckingham.files.wordpress.com/2018/07/going-critical.pdf . Acesso em: 6 set. 2021.

BRASIL. Constituição da República Federativa do Brasil de 1988. Brasília, DF: Presidência da República, 2016. Disponível em: http://www.planalto.gov.br/ccivil_03/Constituicao/Constituiçao.htm. Acesso em: 12 jul. 2021.

BRASIL. Ministério da Educação. Base Nacional Comum Curricular: Educação é a base. Brasília, DF: MEC, 2018. Disponível em:

http://basenacionalcomum.mec.gov.br/images/BNCC_EI_EF_110518_versaofinal_site. pdf. Acesso em: 11 jun. 2021.

CARVALHO, P. M. Podcast: Novas possibilidades sonoras na Internet. In:

INTERCOM - CONGRESSO BRASILEIRO DE CIÊNCIAS DA COMUNICAÇÃO, 34, 2011, Recife, PE. Anais... Disponível em:

https://www.intercom.org.br/papers/nacionais/2011/resumos/R6-2849-1.pdf. Acesso em: 5 dez. 2021.

CGIB - Comitê Gestor da Internet no Brasil. Banda larga no Brasil: Um estudo sobre a evolução do acesso e da qualidade das conexões à Internet. São Paulo: Comitê Gestor da Internet no Brasil, 2018.

FANTIN, M. Mídia-educação: Aspectos históricos e teórico-metodológicos. Olhar de professor, Ponta Grossa, v. 14, n. 1, p. 27-40, 2011. Disponível em http://www.revistas2.uepg.br/index.php/olhardeprofessor . Acesso em: 5 jun. 2021.

IBGE - Instituto Brasileiro de Geografia e Estatística. Pesquisa nacional por amostra de domicílios contínua: Acesso à internet e à televisão e posse de telefone móvel celular para o uso pessoal 2018. Rio de Janeiro: IBGE, 2020.

KLERING, E. H.; ROSA, L. H.; KERSCH, D. F. Multiletramentos em tempos de ensino remoto: o trabalho com podcasts. In: KERSCH et al. (Orgs.). Multiletramentos na pandemia: Aprendizagens na, para a e além da escola. São Leopoldo, Casa Leiria, 2021. p. 101-112.

MINAYO, M. C. S. (Org.). Pesquisa social: Teoria, método e criatividade. Petrópolis: Vozes, 2002. 
OLIVEIRA, I. A.; OLIVEIRA, S. A.; CARVALHO, S. R. Podcast como recurso pedagógico no ensino remoto. Revista Aproximação, v. 2, n. 56-64, p. 56-64, 2020.

PRIMO, A. Para além da emissão sonora: As interações no podcasting. Intexto, Porto Alegre, v. 2, n. 13, p. 1-23, jul./dez., 2005.

SOUZA, D. M.; SILVA, A. C.; PIRES, G. D. L. Construindo diálogos em mídiaeducação e Educação Física: Algumas reflexões a partir de estudos do observatório da mídia esportiva/UFSC. Revista Conhecimento Online, Novo Hamburgo, v. 1, n. 1, p. 22-43, set 2009. Disponível em:

https://periodicos.feevale.br/seer/index.php/revistaconhecimentoonline/article/view/120. Acesso em: 7 dez. 2021.

STEVANIM, L. F. Exclusão nada remota: Desigualdades sociais e digitais dificultam a garantia do direito à educação na pandemia. RADIS, n. 215, p. 10-15, ago 2020.

Disponível em: https://www.arca.fiocruz.br/handle/icict/42947. Acesso em: 2 jul. 2021.

TRIPP, D. Pesquisa-Ação: Uma introdução metodológica. Educação e Pesquisa, São Paulo, v. 31, n. 3, p. 443-466, set./dez., 2005. 